\title{
Demand for redistribution, support for the welfare state, and party identification in Austria
}

\author{
Andreas Kuhn
}

Published online: 19 March 2010

(C) Springer Science+Business Media, LLC. 2010

\begin{abstract}
This paper describes subjective wage inequality and the demand for redistribution in Austria using individuals' estimates of occupational wages from the International Social Survey Program. Although these estimates differ widely across individuals, the data clearly show that most individuals would like to decrease wage inequality, relative to the level of inequality which they perceive to exist. The empirical analysis also shows that the demand for redistribution is strongly associated not only with variables describing self-interested motives for redistribution, but also with perceptions of and social norms with respect to inequality. Further, the demand for redistribution is a strong predictor for whether an individual is supportive of redistribution by the state. On the other hand, however, I find almost no evidence for an empirical association between the demand for redistribution and individuals' party identification.
\end{abstract}

Keywords Subjective inequality measures - Demand for redistribution . Support for the welfare state $\cdot$ Party identification

JEL classification D31 $\cdot$ D63 $\cdot$ H50

\section{Introduction}

In the mid-2000s, taxes and transfer payments reduced inequality in household income among OECD member countries by about 34\% on average (OECD 2008). This simple figure underlines that governments typically exert substantial influence on the distribution of market income through the collection of taxes and the

\footnotetext{
A. Kuhn $(\bowtie)$

Institute for Empirical Research in Economics, University of Zurich and IZA, Mühlebachstrasse 86, 8008 Zurich, Switzerland e-mail: kuhn@iew.uzh.ch
} 
provision of transfer payments. This holds also true for Austria, which will be the focus of the empirical part of this paper, and for which the corresponding figure is $39 \%$. If we start from the premise that political outcomes, such as the factual amount of redistribution, must somehow relate to individuals' preferences over redistribution (e.g. Borck 2007), the question comes up whether and to what extent the actual amount of redistribution mirrors individuals' perceptions of wage inequality as well as their normative beliefs of the just distribution of wages, and how these perceptions and beliefs translate into the political and economic outcomes.

Indeed, recent theoretical work in economics has convincingly pushed the idea that the amount of redistribution is linked to individuals' attitudes towards distributive justice (Alesina and Angeletos 2005) and to individuals' perception of whether differences in earnings are primarily due to either luck or due to individual effort (Bénabou and Tirole 2006), respectively. Such theoretical arguments are supported by some interesting empirical evidence on the assumed link between social norms and beliefs on the one hand and economic and political outcomes on the other hand. For example, Di Tella et al. (2007) analyze a situation which randomly granted legal land titles to some land squatters near Buenos Aires, which secured those squatters endowments (in stark contrast to those squatters that were not granted land titles). Their analysis shows that those squatters who were given legal land titles developed more materialist and individualistic beliefs than their unlucky but otherwise identical counterparts. A recent paper by Giuliano and Spilimbergo (2009) even shows that individuals who grow up during a recession have different beliefs than individuals growing up in an economic boom. The reverse channel, running from norms to outcomes, has been studied in Stutzer and Lalive (2004). They use regional variation in a national referendum on the level of unemployment benefits in Switzerland as a measure for the norm not to work off public benefits. Their analysis shows that the social norm to work has a significant impact on average unemployment duration.

Most of the available empirical evidence on the issue, however, rather focuses on the determinants of individuals' demand for redistribution and their support for the welfare state (Alesina and Giuliano 2009; Alesina and La Ferrara 2005; Corneo and Grüner 2002; Fong 2001). These studies typically find that attitudes towards the welfare state and individuals' perceptions of which factors determine one's income are all associated with the demand for redistribution. For example, people who think that luck is an important determinant of income tend to be more in favor of redistribution. A second typical finding is that income by itself appears to be a surprisingly poor predictor of the demand for redistribution, given its prominent role in the economic literature (e.g. Meltzer and Richard 1981). In an interesting take on the issue Alesina and Fuchs-Schündeln (2007) additionally stress the role of the prevailing economic and political institutions on individual preferences, comparing individuals' attitudes from former East and West Germany. They find that East Germans are much more supportive of the state than West Germans and that it will take a couple of generations until attitudes will converge between the two regions.

This abundance of empirical evidence on the determinants of the demand for redistribution notwithstanding, and even though it seems an obvious task to link 
people's preferences over redistribution with their party identification, evidence on the hypothesized link between attitudes and norms on the one hand and political outcomes on the other hand is scarce. ${ }^{1}$ Alesina and Angeletos (2005) provide some tentative empirical evidence on the relation between the belief that luck determines income and individuals' political orientation, i.e. they show that individuals who believe that luck determines income tend to be found left on the political spectrum. Guiso et al. (2006) make the connection between preferences and political outcomes explicit, showing that the actual amount of redistribution and preferences are indeed related to each other. Kuhn (2009) finds indirect evidence for the link between people's attitudes and political outcomes in Switzerland, showing quite a strong empirical association between various subjective inequality measures and individuals' support for redistribution by the state. Moreover, he finds a substantial impact of these inequality measures on individuals' party identification.

In this paper I will use a simple and intuitive conceptual framework to measure inequality from an individual's subjective point of view. Based on the framework I study the association between subjective inequality measures and individuals' support for the welfare state and individuals' stated party preferences, respectively, relying on survey data from Austria. Austria is, inter alia, an interesting country for further inquiry because it belongs to the group of countries with lowest inequality in disposable household income. ${ }^{2}$ I use the conceptual framework suggested by Kuhn (2009), who applied it to Swiss survey data. This framework yields various measures that describe both the perception of actual wage inequality and the normative assessment of the desired wage inequality at the individual level, and it also leads to a very natural conceptualization of the demand for redistribution as the discrepancy between an individual's ethical assessment and his or her actual perception of wage inequality. This contrasts with the available empirical work, which almost exclusively relies on survey questions that directly ask individuals about their attitude towards and support for the welfare state. Compared to these 'conventional' survey questions, which often have multiple meanings, the measure used in this paper has the advantage that it has a clear focus on wage comparisons across different occupations. Moreover, it has the virtue of making the distinction between individuals' actual and ethical wage estimates possible, a conceptual distinction which gets completely lost when using conventional survey measures of the demand for redistribution.

In the following empirical analysis I will study the association between potential motives for redistribution and the proposed measure of the demand for

\footnotetext{
${ }^{1}$ There is some related evidence from political science. First, there is aggregate evidence showing that welfare retrenchment is associated with partisan politics (Allan and Scruggs 2004; Korpi and Palme 2003). At the individual level, there is research showing that individuals' preferences over political issues are associated with party identification (Carsey and Layman 2006; Goren 2005).

2 Inequality in market income in Austria is lower than in most other OECD countries to start with (OECD 2008). This most likely relates to the high degree of centralization of wage bargaining in Austria (e.g. Wallerstein et al. 1997). The structure of wage bargaining also fits the observation that relative wage structures seem to be rather rigid (Hofer et al. 2001) and wage mobility to be rather low (Hofer and Weber 2002). At the same time, however, public transfers are quite weakly targeted. Consequently, the reduction in inequality due to transfers and taxes is comparatively low in Austria, relative to the amount of resources that is involved (OECD 2008).
} 
redistribution. Specifically, I will focus on economic incentives (e.g. individuals' financial self-interest) on the one hand and individuals' perceptions and norms with respect to distributive justice on the other hand. While economists have usually focused on individuals' income as main predictor of their demand for redistribution, recent empirical work suggests that perceptions of the factors that actually determine income and normative beliefs about which factors should determine income are at least as important predictors. For example, several studies have shown that people who believe that luck is an important determinant of income tend to have a higher demand for redistribution than, say, people perceiving personal effort as an important determinant of income (e.g. Corneo and Grüner 2002; Fong 2001). Further, in an attempt to provide some tentative empirical evidence on the link between individuals' attitudes toward wage inequality and their political preferences, I study whether these subjective measures are associated with individuals' support for the welfare state. To this end, I estimate the association between individuals' demand for redistribution on the one hand and their support for the welfare state in a more general sense as well as their support for progressive taxation on the other hand. Finally, I check whether these measures are associated with individuals' stated party identification. If people care about distributional issues they will presumably support the political parties with an agenda close to their distributional preferences, and thus one arguably expect that individuals' demand for redistribution is a good predictor of their party identification.

The remainder of this paper is structured as follows. Section 2 shortly describes the data source. Special emphasis is given to individuals' estimates of occupational wages available in these data. In Sect. 3, I will discuss the simple framework suitable for the analysis of subjective inequality measures and the demand for redistribution along with corresponding descriptive statistics. The main empirical analysis is presented and discussed in Sect. 4. Section 5 concludes.

\section{Data}

I use data from the International Social Survey Program (ISSP), an annual survey program aimed at establishing internationally comparable data on several key themes as religion, the role of government and social inequality, inter alia. The ISSP organized its first survey focusing on social inequality in 1987 and a second and a third survey followed in the years 1992 and 1999, respectively (a fourth survey is scheduled for 2009). Although Austria took part in all three surveys, the data on occupational wage estimates that are key for the conceptual framework are not available in the 1992 survey. Because there have also been some changes to the key variables over time I will focus exclusively on the data from 1999 survey.

\subsection{Subjective estimates of occupational wages}

The variables that are key for the subsequent empirical analysis are individuals' subjective estimates of the wages of people working in different occupations. Specifically, individuals were asked to estimate what they thought that people 
Table 1 Individuals' subjective estimates of occupational wages

\begin{tabular}{lcc}
\hline & Actual wage & Ethical wage \\
\hline (a) Bottom group: & $1,170.37(304.40)$ & \\
Unskilled worker & $1,263.61(304.33)$ & $1,411.62(409.06)$ \\
Shop assistant & $1,646.91(423.40)$ & $1,544.12(412.86)$ \\
Skilled worker & & $1,887.64(484.87)$ \\
(b) Top group: & $5,960.82(5,222.48)$ & \\
Doctor & $6,772.14(4,222.56)$ & $5,365.46(3,729.71)$ \\
Judge & $7,892.25(5,666.69)$ & $5,481.61(3,090.27)$ \\
Lawyer & $10,083.33(5,335.44)$ & $5,944.27(4,129.51)$ \\
Minister & $10,983.98(8,889.57)$ & $6,296.60(3,418.85)$ \\
Chairman & $13,574.40(12,619.85)$ & $9,690.27(6,270.98)$ \\
Owner factory & & $9,982.49(9,797.28)$ \\
(c) Respondent's occupation & $1,843.64(1,060.26)$ & $2,074.53(1,209.94)$ \\
Coworker &
\end{tabular}

Notes: Table entries are average estimates of actual and ethical wages (in $€$, gross per month). Standard deviations are given in parentheses. All numbers are based on 707 observations except coworkers' wage estimates which are based on 653 and 658 observations, respectively. See also Appendix A

working in nine different occupations and their coworkers actually earn and ought to earn (before taxes and social security contributions), respectively (Appendix A contains the exact wording of the questions and the list of occupations).

Table 1 shows descriptive statistics for these wage estimates. ${ }^{3}$ According to Table 1, for example, individuals perceive the gross monthly wage of a shop assistant to be about $€ 1,264$ on average, while they on average think that a shop assistant should earn about $€ 1,544$ a month, yielding a difference between desired and perceived wage of about $€ 280$ per month. Note that the real wage of a shop assistant is not the focus of this study because misperceptions of factual wage rates are one important reason why people might demand (different amounts of) redistribution. In the case of a lawyer, by way of comparison, the average perceived monthly wage (about $€ 7,890$ ) is considerably higher than what the average person would judge as appropriate (about $€ 5,940$ only).

Figure 1 plots the average estimates of actual and desired wages for each occupation to make the main features of these estimates more visible. First, people seem to accept rather large differences in wages across occupations on average as there is a very clear-cut ranking of the occupations not only with respect to actual wages, but also with respect to desired wages. Moreover, note also that the ranking of the occupations as regards their just wages is exactly the same as the ranking with respect to their actual wages. Thus people not only think that a lawyer actually earns

\footnotetext{
3 The original wage estimates in the survey are given in units of the former Austrian currency, the Austrian Schilling. To simplify the reading of the table I have converted all numbers into Euros, using the exchange rate at which the Austrian Schilling was replaced by the Euro $(1 €=13.7603 \mathrm{ATS})$. Since almost all of the subsequent analysis is based on relative comparisons, the exact choice of exchange rate does not matter on substantial grounds.
} 


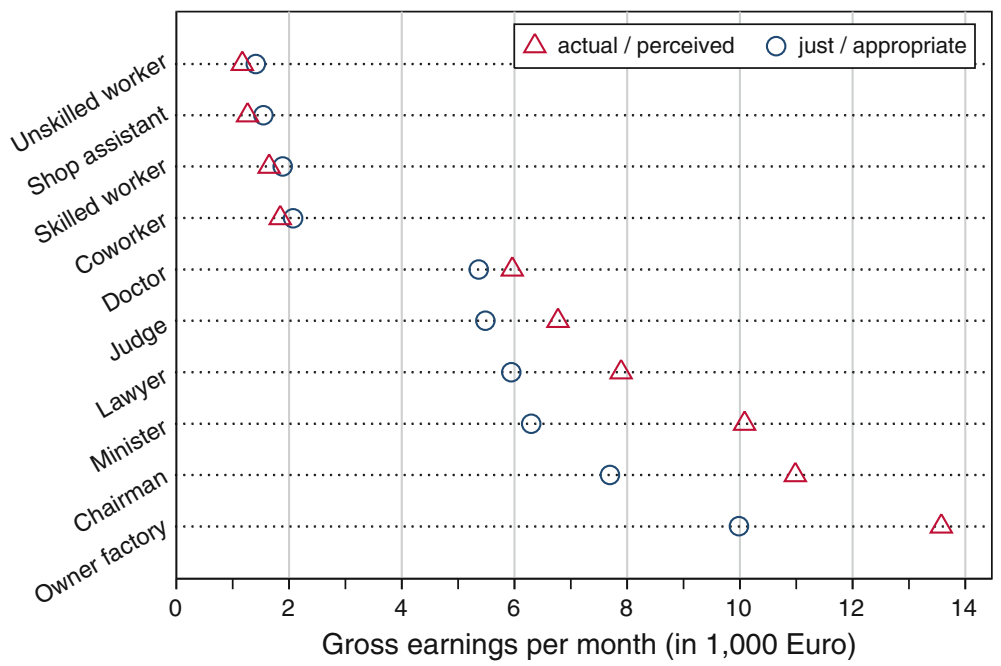

Fig. 1 Individuals' subjective estimates of actual and ethical wages, by occupation. Notes: The triangles correspond to individuals' average estimates of actual occupational wages. The circles shows average estimates of ethical occupational wages. The number of observations equals 707 except in the case of coworkers' actual (ethical) wage, which is based on 653 (658) observations only (see also Table 1)

more than a shop assistant, they also tend to think that a lawyer ought to earn more than a shop assistant. Second, average estimates for actual and desired wages differ considerably from each other within each occupation. However, they do so to a very different degree. For example, the average ethical wage estimate is higher than the actual wage estimate in the case of the shop assistant, while the reverse holds true for the lawyer. Third, there are three occupations (i.e. unskilled worker, shop assistant and skilled worker) for which both actual and ethical wages are comparatively low and for whom ethical wages are higher than actual wages. The reverse holds true for the remaining six occupations, while coworkers' wages fall right in between these two groups.

\section{Conceptual framework}

This section shortly discusses the building blocks of a simple conceptual framework suitable for describing subjective wage inequality and the demand for redistribution. The framework that I use is borrowed from and discussed in more detail in Kuhn (2009).

First note that, to measure objective wage inequality in some subpopulation of size $n$, it is sufficient to observe the corresponding vector of wages:

$$
y=\left\{y_{(1)}, \ldots, y_{(i)}, \ldots, y_{(n)}\right\},
$$

as most inequality indices are a function of $y$ only. The measurement of subjective wage inequality is a simple generalization in that the vector of wages now becomes a function of the evaluation of these wages by a specific individual: 


$$
y(i)^{w}=\left\{y(i)_{(1)}^{w}, \ldots, y(i)_{(i)}^{w}, \ldots, y(i)_{(n)}^{w}\right\}
$$

Thus, subjective inequality may differ across individuals because individuals may have different evaluations of occupational wages. As a consequence, while objective inequality can be summarized by one inequality measure only, subjective inequality is described by a distribution of inequality indices across individuals. The second distinguishing feature is that subjective wage data allow the distinction between individuals' estimates of both actual and ethical wages (denoted by superscript $w=a$ and $w=e$, respectively).

Further note that Eq. (2) can be approximated by group-level data, analogous to objective wage data again. In the simplest possible case there are only two groups of occupations, representing the lower and the upper part of the occupational distribution. In this case, the wage distribution across occupations is fully described by three different moments only (note that $f_{\text {top }}=\left(1-f_{\text {bottom }}\right)$ because there are only two groups):

$$
\begin{gathered}
\left(\bar{y}(i)_{\mathrm{bottom}}^{a}, \bar{y}(i)_{\mathrm{top}}^{a}, f_{\mathrm{bottom}}\right), \text { and } \\
\left(\bar{y}(i)_{\mathrm{bottom}}^{e}, \bar{y}(i)_{\mathrm{top}}^{e}, f_{\mathrm{bottom}}\right),
\end{gathered}
$$

with $\bar{y}(i)_{\text {bottom }}$ and $\bar{y}(i)_{\text {top }}$ denoting an individual's wage estimate for the lower and the upper part of the occupational distribution, respectively. Formula (3a) is used to approximate an individual's perceived distribution of actual wages while formula (3b) approximates his or her imagination of the ethical wage distribution. ${ }^{4}$ Individuals' estimates of actual and ethical wages for different occupations as well as the distribution of occupations in the sample are used to compute the three moments in (3a) and (3b), respectively. ${ }^{5}$ These numbers in turn are sufficient to compute the Gini coefficient for both actual and ethical wages at the individual level as follows (as shown in Kuhn 2009):

$$
G(i)^{w}=f_{\text {bottom }}-q^{w}(i)_{\text {bottom }},
$$

where $w=a(w=e)$ again refers to the actual (ethical) wage distribution and where $q(i)_{\text {bottom }}^{w}$ equals the wage share of the bottom group. Because the group weights are assumed to be the same for the actual and the ethical wage distribution as well as across individuals, all differences between individuals as regards their evaluation of wage inequality must be due to differences in their estimates of occupational wages. $^{6}$

\footnotetext{
${ }^{4}$ Several researchers have pointed out that social justice must be a function of an individual's perceptions and ethical beliefs. See Jasso (1999), Osberg and Smeeding (2006), and Sen (2000), among others.

${ }^{5}$ More specifically, $\bar{y}(i)_{\text {bottom }}$ is computed as the simple average of an individuals' wage estimates for a shop assistant, an unskilled worker, and a skilled worker. Analogously, $\bar{y}(i)_{\text {top }}$ is computed as the average of an individual's wage estimates for the remaining six white-collar occupations. See also Table 1 and Appendix A. Finally, the fraction of individuals belonging to the bottom group, $f_{\text {bottom }}$, is estimated from the occupational distribution in the sample using the International Standard Classification of Occupations.

${ }^{6}$ It is well known that the Gini coefficient based on grouped data will generally be lower than if based on individual level data due to convexity of the Lorenz curve (e.g. Gastwirth and Glauberman 1976), unless there is no within-group variation of wages.
} 
In what follows, I use the desired reduction in the perceived level of actual wage inequality as measure for the demand for redistribution, multiplied by -1 to fit the intuition that higher values of the measure indicate a higher demand for redistribution:

$$
R(i)=-1 \cdot\left[\frac{G(i)^{e}}{G(i)^{a}}-1\right]=\left[1-\frac{G(i)^{e}}{G(i)^{a}}\right]
$$

Because the population weights are fixed, the only reason why $G(i)^{e}$ and $G(i)^{a}$ can possibly differ and thereby give rise to any demand for redistribution is because the ethical wage shares of the two group differ from the corresponding actual wage shares. $^{7}$ Moreover, $R(i)$ has the feature that a higher perceived inequality and a lower desired inequality, respectively, lead to a higher demand for redistribution ceteris-paribus. It is exactly this feature of the measure that seems to perfectly fit our own intuition about the demand for redistribution. Note that for most of the measures used in the empirical literature such ceteris-paribus comparisons are not possible because they confound these two dimensions.

However, it must be noted that $R(i)$ is only informative about the degree of desired wage equalization across different occupations. An important limitation of this measure therefore is that it tells us nothing about desired redistribution from the economically active part of the population to individuals who are not in the labor force (e.g. unemployed workers, retirees, children) or about redistribution through the provision of public goods (e.g. education).

\subsection{Descriptive statistics}

Table 2 shows descriptive statistics for the different subjective inequality indices discussed in the preceding section. As expected, the average subjective Gini coefficient describing individuals' perceived wage distribution is positive on average (about 0.335) and remarkably higher than the average Gini coefficient describing the desired wage distribution (which is equal to about 0.229).

It is also interesting to note that all individuals perceive at least some wage inequality and that only a tiny fraction (about $0.4 \%$ ) of all individuals judges absolute equality as their desired wage distribution, suggesting that absolutely equal wages across occupations is in general not judged as a fair distribution. Consequently, individuals demand a positive and quantitatively significant amount of redistribution on average. Average demand for redistribution equals 0.311 , implying that individuals want to decrease wage inequality by about one third, relative to the level of inequality that they perceive to exist. Table 2 also shows the fraction of individuals exhibiting a negative, null or positive demand for redistribution (see below). Not surprisingly, however, an overwhelming majority of individuals desires a positive amount of redistribution.

\footnotetext{
7 I have re-run part of the analysis using the difference between the two inequality indices as a measure for desired redistribution, i.e. using $\Delta G(i)=-1 \cdot\left[G(i)^{j}-G(i)^{a}\right]$ as dependent variable. The results turn out to be qualitatively the same (results not shown).
} 
Table 2 Subjective inequality measures and the demand for redistribution

\begin{tabular}{lll}
\hline & Mean & Standard deviation \\
\hline Gini coefficient, actual wage distribution & 0.335 & 0.120 \\
$\mathbf{1}($ Actual Gini $=0$ ) & 0.000 & \\
Gini coefficient, ethical wage distribution & 0.229 & 0.110 \\
$\mathbf{1}($ Ethical Gini $=0)$ & 0.004 & 0.233 \\
Demand for redistribution & 0.311 & \\
$\mathbf{1}($ Demand $<0)$ & 0.047 & \\
$\mathbf{1}($ Demand $=0)$ & 0.033 & \\
$\mathbf{1}(0<$ Demand $<1)$ & 0.914 & \\
$\mathbf{1}($ Demand $=1)$ & 0.004 & \\
$\mathbf{1}($ Demand $>1)$ & 0.003 &
\end{tabular}

Notes: All table entries are based on 707 observations. All wage estimates in panel (a) and (b) are given in $€$. All variables are defined in the main text. $\mathbf{1}(\cdot)$ denotes the indicator function

Panel (a) of Fig. 2 shows the joint distribution of the two subjective inequality measures. This figure shows that there is pronounced heterogeneity not only in the beliefs that people hold, but also in the perceptions they have. Moreover, there is variation in the desired level of inequality for any given level of perceived inequality. Further, it is also clear that most individuals favor a level of wage inequality that is somewhat lower than what they actually perceive, as most of the points lie below the $45^{\circ}$ line (indicating no demand for redistribution at all). Consequently, the resulting distribution of the demand for redistribution takes on positive values for most individuals, as shown in panel (b) Fig. 2. ${ }^{8}$ However, there are also some individuals with a value on the demand for redistribution that is larger than one and some individuals with a negative value on this measure even. Closer inspection of the first case reveals that a demand higher than one results for individuals who would like to overturn the ranking of the two groups (however, there are only two observations where this happens). A negative value for the demand for redistribution most often results from individuals' desire to increase all wages, but the wages of the top group to an even higher degree than the wages of the bottom group. Thus, because the overall wage level is not held constant, a negative demand is not exactly the same as a regressive transfer.

\section{Empirical analysis}

\subsection{Motives for demanding redistribution}

Given the huge amount of heterogeneity in both inequality perceptions and normative beliefs, it is not really evident whether individuals' perceptions and

\footnotetext{
${ }^{8}$ Figure 2 makes it also clear that it is perfectly appropriate to use standard linear regression models in this case, as opposed to the conventional measures that have been analyzed in the literature so far. These measures are most often of ordinal nature only and thus require more sophisticated (but also more difficult to interpret) statistical models.
} 

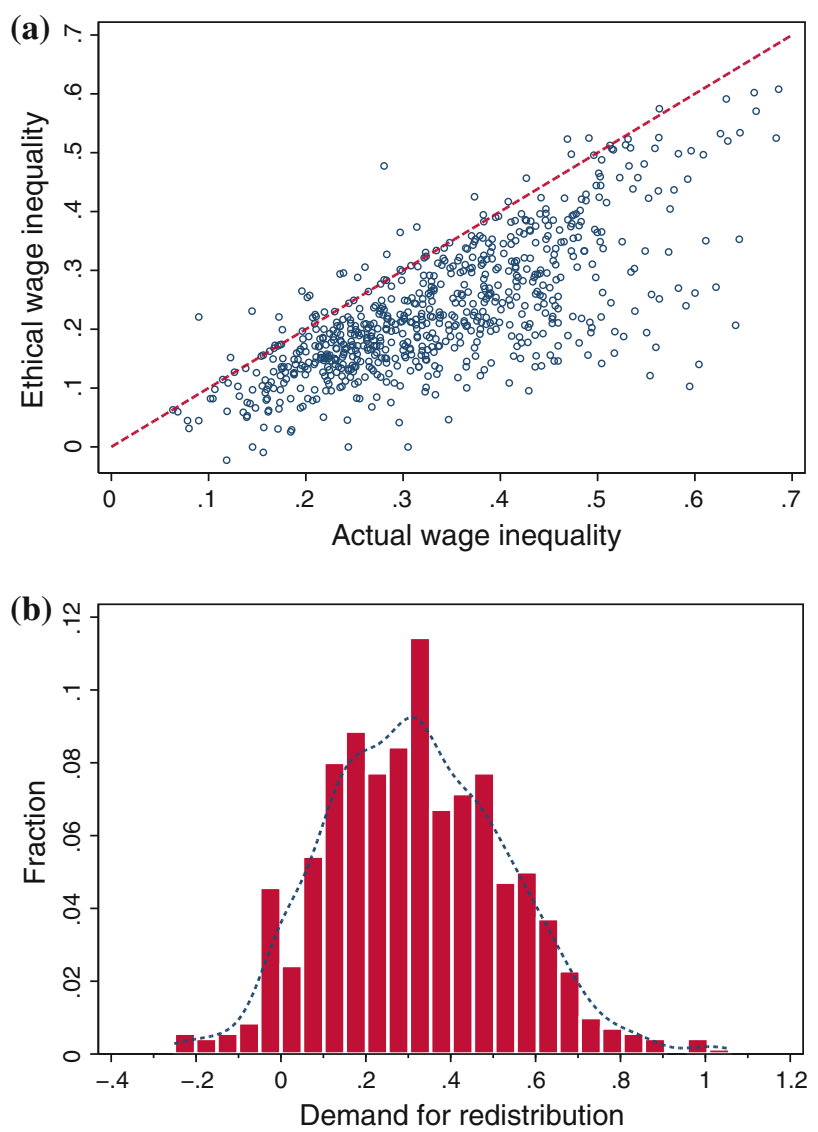

Fig. 2 Subjective inequality measures. a Ethical versus actual inequality. b Demand for redistribution. Notes: The figure in panel (a) shows the joint distribution of the two subjective wage inequality measures, as defined in Eq. (4) in the text. The dashed line corresponds to the $45^{\circ}$ line. Panel (b) shows the distribution of the demand for redistribution, as defined in Eq. (5). The dotted line shows the kernel density estimate with gaussian kernel and bandwidth of about 0.052 . Seven observations (with a value lower than -0.25 ) have been excluded for drawing the figure in panel (b)

beliefs have some structure at all. In a first step, I therefore investigate different potential motives for demanding redistribution that have been put forward in the literature (Fong et al. 2005, survey the relevant lines of argument).

Clearly, the one motive for redistribution that has received most attention from economists is individuals' financial self-interest (e.g. Meltzer and Richard 1981). Because individuals act self-interested, simple models of redistribution predict that an individual's support for redistribution decreases with his or her personal income (Roberts 1977). As it turns out, however, personal income is a surprisingly poor predictor of the support for redistribution (Corneo and Grüner 2002; Fong 2001). One potential explanation is that the impact of own income is not as immediate as in a simple theoretical model. For example, individuals' income may change over time 
for a variety of reasons. Therefore, the poor may refrain from taxing the rich if they believe that they may become rich sometime in the future and people who have moved upward within the income distribution for whatever reason will arguably tend to think that own effort pays off. For these reasons it has been argued that income mobility is one important mediating factor (Bénabou and Ok 2001; Piketty 1995). A second important explanation for the weak effect of income is based on the argument that relative comparisons, and not differences in absolute income, are key to individuals' satisfaction with their income situation (Clark and Oswald 1996; Senik 2005), and the same argument may apply to the support for redistribution. More specifically, it is probably not so much the absolute level of income, but the satisfaction with own income that impacts the demand for redistribution.

Previous empirical research has also consistently shown that individuals' perceptions and normative beliefs are at least as important predictors of the support for redistribution as people's income. I therefore also include measures of the most important principles with respect to distributive justice, namely equity (or proportionality) and needs (Dawes et al. 2007), as well as people's perceptions of the extent to which either acquired (e.g. education) or ascribed (e.g. gender) features actually are important in determining one's pay.

Broadly speaking, then, I model the demand for redistribution as a function of individuals' self-interest as well as of their inequality perceptions and their normative beliefs in ethical principles related to distributional justice. The econometric model thus takes the following form:

$$
R_{i}=\beta_{0}+\text { self-interest }_{i} \gamma_{1}+\text { beliefs }_{i} \gamma_{2}+\text { controls }_{i} \beta+\epsilon_{i},
$$

where $R_{i}$ is the demand for redistribution as given by Eq. (5). I try to include measures that match the theoretical predictors as close as possible (see Appendix A

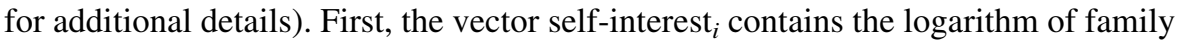
income, a measure for a worker's dissatisfaction with his own income, as well as a variable measuring an individual's past experience of upward mobility. On would expect a negative effect on $R_{i}$ in the case of log family income and mobility, and a positive effect in the case of income dissatisfaction. A second group of regressors (beliefs ${ }_{i}$ ) includes individuals' perceptions of how wages are determined in reality and their normative beliefs with respect to the just distribution of wages (subsumed under the vector beliefs $s_{i}$ ). More specifically, there are two different variables describing individuals' perceptions. The first variable measures whether people think that acquired skills or active inputs, like educational attainment and personal effort, are in reality relevant for determining pay. The second variable measures the weight that people attach to ascribed skills or inputs beyond an individual's control, like knowing the right people, in determining one' wage. Moreover, I include two variables that try to measure the principles of proportionality and needs, respectively. To this end, I have constructed a first variable that measures the extent to which an individual thinks that things like a worker's schooling and effort should ultimately determine his or her pay. A second variables tries to capture the extend to which an individual beliefs that things like the number of children should be important for determining pay. Here, I would expect that both the perception of and the belief in effort being important should reduce the demand for redistribution 
while the perception of and the belief in needs should increase the demand for redistribution. Finally, the third vector $\left(\operatorname{controls}_{i}\right)$ includes additional control variables that are likely correlated with potential but unobserved confounding variables like, for example, risk aversion. ${ }^{9}$

Estimates of $\gamma_{1}$ and $\gamma_{2}$ are shown in Table 3. The first two models focus on selfinterested motives only, with and without controlling for background characteristics, respectively. The next two models focus on the effects of the variables describing individuals' beliefs and perceptions (again, with and without background controls). Finally, both sets of regressors are included in the last three models, and the ultimate model additionally includes the interaction between log family income and income dissatisfaction to check whether the effect of income depends on the an individual's assessment of his or her wage.

The first row shows that, as expected, income has a negative and statistically significant effect on the demand for redistribution. The corresponding parameter estimates range between about -0.045 and -0.075 . The effect of income is actually quite large in economic terms as the parameter estimates imply an elasticity of the demand for redistribution with respect to income of about -0.14 to about -0.24 , if evaluated at the mean value of the dependent variable. Nonetheless, the predicted average demand for redistribution for individuals with highest income is still positive. ${ }^{10}$ Interestingly, income dissatisfaction has a large positive effect, i.e. individuals who think that they should earn more than they actually do have a higher demand for redistribution. The model in the last column adds the interaction term between the log of income and income dissatisfaction to the set of regressors. Interestingly, the interaction term turns out to be negative, implying that the effect of income is the more negative for those individuals with higher income dissatisfaction. Contrary to expectation, however, the effect of the mobility index turns out to be insignificant and essentially zero in economic terms.

The next four rows show the estimated effect of individuals' beliefs and perceptions. The two belief variables, labelled needs and effort, both have the expected sign and quite strong effects on the demand for redistribution across all specifications. A one standard deviation increase in the belief that needs should be important in determining pay, for example, increases the demand for redistribution by about 0.03 (which corresponds to a relative increase of about 9\%). The belief in effort has the expected negative sign and, similarly, has also quite a strong effect on the dependent variable. Increasing effort by one standard deviation results in an increase of about -0.029 (corresponding to a relative decrease of about 9.5\%). Turning to individuals' perceptions of how pay is actually determined, only one of

\footnotetext{
9 The full list of background controls is the following: Age (in years), a female dummy, educational attainment (in years), the number of persons in the household, two dummy variables indicating employment and retirement status, respectively, a dummy for living in an urban/suburban region, and a set of dummies for the state of residence. Table 6 provides summary statistics for these variables.

${ }^{10}$ For example, using the estimates from the model shown in column (6), the average predicted demand for redistribution is 0.287 for individuals in the highest income bracket. Although this number is clearly much lower than the average demand of the poorest individuals in the sample (sample average of 0.416), these individuals still have a positive demand for redistribution on average.
} 


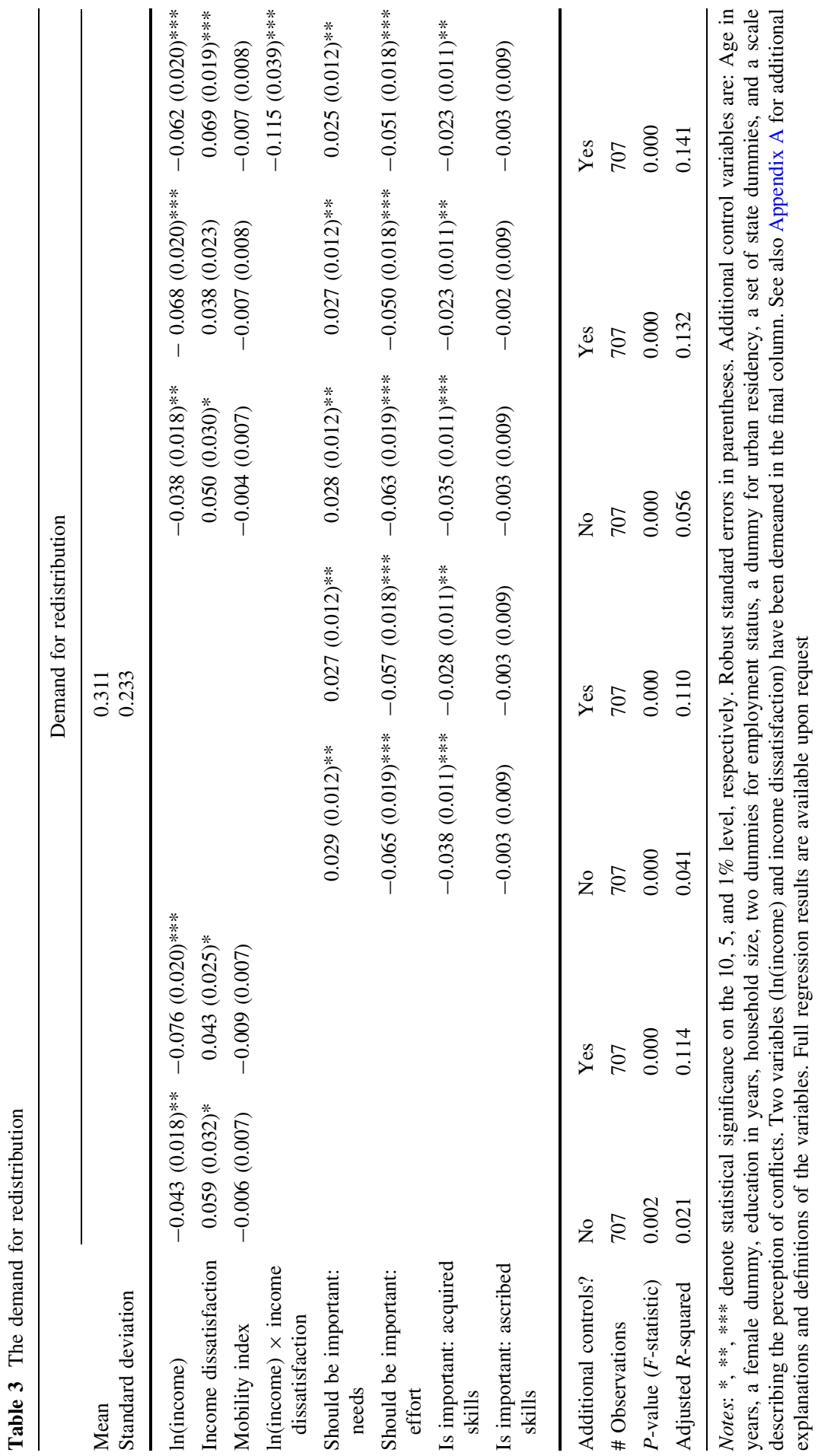


the two included variables, i.e. the perception that 'acquired' skills, has any statistical impact on the demand for redistribution. Again, a hypothetical increase of one standard deviation leads to a predicted decrease in the dependent variable of about 0.026 , which corresponds roughly to a relative decrease of $8.3 \%$.

The results from Table 3 yield a consistent picture: all models yield the same results qualitatively, whether background controls are included or not. Further, all regressors of interest have the expected sign, except the index of mobility and the variable describing whether an individual thinks that ascribed skills are important for getting ahead which are not statistically different from zero. In both cases, this seems to be a result from point estimates that are essentially zero (and not because the precision of the estimates is low). Overall, these results also fit well into the previous empirical literature (e.g. Corneo and Grüner 2002; Fong 2001).

\subsection{Support for the welfare state}

Even though most individuals have a latent demand for redistribution, it is a-priori not clear whether these individuals also think that the government should be doing something about it. Further, as mentioned in Sect. 3 before, support for the welfare state and thus redistribution in a more general sense also includes redistribution from the working population to people that are economically not active (e.g. retirees).

To assess the empirical link between individuals' latent demand for redistribution and their support for the welfare state, I regress two simple measure of individuals' support for the welfare state on some of the subjective inequality measures that have been discussed before. ${ }^{11}$ I then run several regression models similar to Eq. (6), only that now the support for redistribution by the state is the dependent variable and the demand for redistribution $R_{i}$ is the key regressor:

$$
\text { support }_{i}=\beta_{0}+R_{i} \alpha+\text { self-interest }_{i} \gamma_{1}+\text { beliefs }_{i} \gamma_{2}+\text { controls }_{i} \beta+\epsilon_{i},
$$

where support $_{i}$ is one of two distinct measures for individuals' support for redistribution by the state. I am now mainly interested in parameter $\alpha$ which quantifies the effect of individuals' subjective inequality perception on their propensity to support redistribution by the state. As shown in the preceding section, the independent variables describing different motives for demanding redistribution quite strongly correlate with $R_{i}$. I therefore also show results when only the background control variables are included as regressors.

Table 4 shows the resulting estimates. The dependent variable in the first two columns is individuals' general support for redistribution by the state, and their specific support for progressive taxation in the remaining two columns. The first model of each panel includes only the socio-demographic controls while the second model additionally includes the measures of self-interested motives for redistribution as well as people's beliefs and norms. We may first note that there is considerable support for redistribution by the state (the average of the dependent

\footnotetext{
11 The first variable is the agreement with the following statement: "It is the responsibility of the government to reduce the differences in income between people with high incomes and those with low incomes." The second variable measures individuals' agreement with the statement that "people with high incomes should pay a larger share of their income in taxes than those with low incomes."
} 
Table 4 Support for redistribution by the state and progressive taxation

\begin{tabular}{|c|c|c|c|c|}
\hline \multirow{3}{*}{$\begin{array}{l}\text { Mean } \\
\text { Standard deviation }\end{array}$} & \multicolumn{2}{|c|}{$\begin{array}{l}\text { "Government should reduce } \\
\text { income differences" }\end{array}$} & \multicolumn{2}{|c|}{$\begin{array}{l}\text { "Richer people should pay higher } \\
\text { taxes" }\end{array}$} \\
\hline & 3.788 & & 4.150 & \\
\hline & 1.141 & & 0.668 & \\
\hline Demand for redistribution & $0.988(0.224)^{* * *}$ & $0.904(0.223) * * *$ & $0.363(0.113)^{* * *}$ & $0.287(0.111)^{* *}$ \\
\hline Controls included? & Yes & Yes & Yes & Yes \\
\hline $\begin{array}{l}\text { Self-interested motives } \\
\text { included? }\end{array}$ & No & Yes & No & Yes \\
\hline Beliefs included? & No & Yes & No & Yes \\
\hline \# observations & 685 & 685 & 685 & 685 \\
\hline$P(F$-statistic $)$ & 0.000 & 0.000 & 0.000 & 0.000 \\
\hline Adjusted $R$-squared & 0.202 & 0.222 & 0.134 & 0.153 \\
\hline
\end{tabular}

Notes: *,**, *** denote statistical significance on the 10, 5, and $1 \%$ level, respectively. Robust standard errors in parentheses. See also notes of Table 3. The dependent variable in the first two columns is the (dis)agreement to the statement: "It is the responsibility of the government to reduce the differences in income between people with high incomes and those with low incomes." The dependent variable in the last two columns is the (dis)agreement with the statement that "people with high incomes should pay a larger share of their income in taxes than those with low incomes." The two dependent variables range from 1 to 5

variable equals 3.78 , on a scale ranging from 1 to 5) and even higher support for proportionally higher taxation of richer people (average of 4.15 on a scale from 1 to 5$)$.

We can see that the demand for redistribution has a large positive and significant effect on individuals' support for redistribution by the state, i.e. people who desire a more equal distribution of occupational wages tend to be more in favor of redistribution by the state. This holds true regardless of the specific set of control variables that are included in the model, although the point estimate is somewhat reduced by the inclusion of additional controls (only including background controls yields a point estimate of 0.988 , while additionally controlling for self-interested motives and beliefs leads to a smaller point estimate of 0.904). The size of the effect turns out to be large in substantive terms as the elasticity of the support for redistribution by the state with respect to the demand for redistribution equals about $7.5 \%(=100 \%[(0.311 \cdot 0.904) / 3.788])$ if evaluated at mean values (and using the point estimate of the second column).

Similar results are obtained for people's support for progressive taxation. Individuals with a high latent demand for redistribution tend to be more supportive of taxing the rich. Also as before, the corresponding effects are large in economic terms. The point estimate shown in the last column implies an elasticity of the support for progressive taxation with respect to the demand for redistribution of about $2.2 \%(=100 \%[(0.311 \cdot-0.287) / 4.150])$. 


\subsection{Party identification}

Political parties in Austria differ markedly if positioned on a simple left-right scale by national political experts (e.g. Castles and Mair 1997; Huber and Inglehart 1995). ${ }^{12}$ If individuals' demand for redistribution really shapes government's action towards inequality, then we would also expect an association between the subjective inequality measures and individuals' preferences over political parties. On the other hand, however, politics is not exclusively about issues of redistribution. Indeed, 'new politics' (e.g. new versus traditional culture, immigration, environmental issues) play an important role in Austria and interfere with economic issues (Knutsen 1998). Most notably in this respect is probably the evolution of support for the right-wing Austrian Freedom Party, which moved from the center to the far right and which managed to attract a significant fraction of blue-collar workers as their supporters mainly by "combining opposition to immigration with free-market economic and socio-cultural conservatism" (McGann and Kitschelt 2005, p.148). Thus it may also be the case that these 'new politics' issues are more important than redistributive issues. ${ }^{13}$

It is therefore an empirical question whether individuals' demand for redistribution predicts their party preferences. I therefore estimate the association between the demand for redistribution and individuals' stated preference over different political parties:

$$
\mathbf{1}\left(\operatorname{Party}_{i}=j\right)=\beta_{0}+R_{i} \alpha+\text { self-interest }_{i} \gamma_{1}+\text { beliefs }_{i} \gamma_{2}+\text { controls }_{i} \beta+\epsilon_{i},
$$

where the dependent variable $1\left(\operatorname{Party}_{i}=j\right)$ is a dummy variable indicating whether individual $i$ would vote for party $j .{ }^{14}$ The variables on the right-hand side are exactly the same as before. For the ease of interpretation, I estimate the parameters from Eq. (8) by ordinary least squares instead of using a nonlinear model like, for example, a probit. ${ }^{15}$ In the analysis, I only consider the four political parties that had the largest share of votes at the time the survey was administered. These are the Austrian Social Democrats ("Sozialdemokratische Partei Österreichs", SPÖ), the conservative Austrian People's Party ("Österreichische Volkspartei", ÖVP), the right-wing Austrian Freedom Party ("Freiheitliche Partei Österreichs", FPÖ), and the Green Party ("Die Grünen"). Note that the sample size is somewhat reduced because of missing information on party preference for some individuals: there remain 534 out of the original 707 observations.

\footnotetext{
12 For the year 1993, mean positions range from 2.86 (The Green Party) to 8.64 (FPÖ), on a scale from 0 to 10. See Appendix B in Huber and Inglehart (1995).

13 Indeed, the positions of the two big parties in Austria (ÖVP, SPÖ) have converged to a significant degree, at least as regards social policy, as argued by Seeleib-Kaiser et al. (2005). This is consistent with Knutsen (1998) who shows that, from the standpoint of political experts, the SPÖ has moved to the right in recent years.

14 I have also re-estimated the same models using only those individuals who do state preference for any political party. The results are qualitatively the same as the ones obtained from using all available observations (results not shown).

15 I have also estimated a series of probit models and a multinomial logit model. It turns out that the results are virtually the same (results available upon request). I therefore stick to the model with the easiest interpretation.
} 
Table 5 Stated party preference

\begin{tabular}{|c|c|c|c|c|c|c|c|c|}
\hline \multirow{3}{*}{$\begin{array}{l}\text { Mean } \\
\text { Standard deviation }\end{array}$} & \multicolumn{2}{|l|}{ SPÖ } & \multicolumn{2}{|l|}{ ÖVP } & \multicolumn{2}{|l|}{ FPÖ } & \multicolumn{2}{|c|}{ The green party } \\
\hline & 0.324 & & 0.243 & & 0.109 & & 0.124 & \\
\hline & 0.468 & & 0.430 & & 0.311 & & 0.329 & \\
\hline $\begin{array}{l}\text { Demand for } \\
\text { redistribution }\end{array}$ & $\begin{array}{l}0.071 \\
\quad(0.081)\end{array}$ & $\begin{array}{l}0.093 \\
(0.083)\end{array}$ & $\begin{array}{c}-0.135^{*} \\
(0.084)\end{array}$ & $\begin{array}{r}-0.106 \\
(0.067)\end{array}$ & $\begin{array}{l}0.017 \\
\quad(0.067)\end{array}$ & 0.033 & $\begin{array}{l}0.021 \\
\quad(0.048)\end{array}$ & $\begin{array}{l}0.006 \\
(0.051)\end{array}$ \\
\hline $\begin{array}{l}\text { Controls } \\
\text { included? }\end{array}$ & Yes & Yes & Yes & Yes & Yes & Yes & Yes & Yes \\
\hline $\begin{array}{l}\text { Self-interested } \\
\text { motives included? }\end{array}$ & No & Yes & No & Yes & No & Yes & No & Yes \\
\hline Beliefs included? & No & Yes & No & Yes & No & Yes & No & Yes \\
\hline \# observations & 534 & 534 & 534 & 534 & 534 & 534 & 534 & 534 \\
\hline$P$-value ( $F$-statistic) & 0.000 & 0.000 & 0.000 & 0.001 & 0.005 & 0.023 & 0.000 & 0.000 \\
\hline Adjusted $R$-squared & 0.058 & 0.064 & 0.063 & 0.059 & 0.026 & 0.029 & 0.142 & 0.142 \\
\hline
\end{tabular}

Notes: $*, * *, * *$ denote statistical significance on the 10,5 , and $1 \%$ level, respectively. Robust standard errors in parentheses. See also notes of Table 3

Estimation results are given in Table 5. The first column of each panel shows estimates when only baseline controls are included while the second column shows estimates that also control for variables describing individuals' financial self-interest and their perceptions and beliefs. As before, I show both sets of results because some of the regressors and the demand for redistribution are highly correlated.

Quite surprisingly, and in stark contrast to the results for individuals' support for redistribution by the state, all key parameters turn out to be statistically insignificant (the only exception is a significant effect of the demand for redistribution on the probability of voting for the ÖVP). However, this effect also turns insignificant once beliefs and perceptions are included as regressors. Moreover, the insignificance seems to be mainly a result of small point estimates, and less so a result of imprecision of those estimates. For example, the point estimate for the effect of the demand for redistribution on stated party preference for the social-democratic party is 0.071 , which yields a predicted change in the probability of stating preference for the social-democratic party of 1.65 percentage points for a hypothetical increase in the demand for redistribution of one standard deviation (which equals 0.233). ${ }^{16}$ In most cases, the lack of statistical significance is a result of small point estimates, and not so much a result of large standard errors.

It thus appears that concerns about wage inequality-although such concerns are clearly present, as shown in the preceding sections - is not an important determinant of individuals' party identification with the exception of the support for the ÖVP. Thus it indeed appears that issues such as immigration and the environment, inter alia, dominate economic issues with respect to party identification.

\footnotetext{
${ }^{16}$ The same calculation for the largest effect, i.e. the effect running from the demand for redistribution on the probability of stating preference for the conservative party, yields a predicted change of slightly more than three percentage points.
} 


\section{Conclusions}

In this paper, I study subjective estimates of wage inequality and the demand for redistribution in Austria, using a simple empirical framework that mainly builds on individuals' estimates of both actual and ethical wages of several specific occupations. This framework explicitly distinguishes between individuals' perceptions and normative beliefs as regards the distribution of wages, which then leads to a natural measure of the demand for redistribution as the desired reduction in the perceived level of wage inequality.

A first key result of this paper is that most individuals would prefer a distribution of occupational wages that is more equal than the distribution they perceive to actually exist, and this desired reduction in overall wage inequality is driven by both a desire to increase wages at the bottom and to decrease wages at the top of the distribution. Further, and in line with previous evidence, self-interested motives do explain part of the variation in the demand for redistribution, but perceptions of inequality and normative beliefs with respect to inequality appear to be at least as important.

As expected, the various subjective inequality measures in turn are substantially significant predictors of individuals' support for redistribution by the state. Individuals with a high demand for redistribution, with a high level of perceived wage inequality or with a low level of ethical wage inequality tend to support intervention by the government in order to reduce existing inequalities. On the other hand, however, there is no substantial association between subjective inequality indices and individuals' party identification.

Acknowledgments I thank Johann Brunner, Josef Zweimüller, participants at the Annual Meeting of the Austrian Economic Association 2009 in Linz as well as seminar participants in Zurich for helpful comments. I also thank two anonymous referees for helpful comments and suggestions. Financial support by the Austrian Science Fund (National Research Network: "The Austrian Center for Labor Economics and the Analysis of the Welfare State") is gratefully acknowledged.

\section{Appendix A: Variable definitions}

\section{A.1 Occupational wages}

Individuals were asked two questions about occupational wages (the wording is taken from the source questionnaire of the ISSP):

1. "We would like to know what you think people in these jobs actually earn. Please write how much you think they actually earn each month (before taxes and social security contributions). Many people are not exactly sure about this, but your best guess will be close enough."

2. "Next, what do you think people in these jobs ought to be paid. How much do you think they should earn each month (before taxes and social security contributions), regardless of what they actually earn." 
Individuals were then asked to estimate actual and just wages of people working in the following ten jobs (in the same order as in the survey):

1. "A skilled worker in a factory" (skilled worker)

2. "A doctor in general practice" (doctor)

3. "The chairman of a large national company" (chairman)

4. "A lawyer" (lawyer)

5. "A shop assistant in a big store" (shop assistant)

6. "The owner-manager of a large factory" (owner factory)

7. "A judge in the constitutional court" (judge)

8. "An unskilled worker in a factory" (unskilled worker)

9. "A cabinet minister in the Federal Government" (minister)

10. "Your own occupation" (coworker)

The phrasing in parentheses is the corresponding label used in the text, figures and tables. All variables computed from these occupational wage estimates are discussed in detail in Sect. 3 and 1 in the main text.

\section{A.2 Independent variables}

Family income

Family income is only available as a discrete variable with only a few different values. I use the midpoints of these intervals as values on the variable.

\section{Income dissatisfaction}

This variable corresponds to the ratio of just and actual wage for individual $i$ 's coworkers, that is $\left(y(i)_{\text {Coworker }}^{e} / y(i)_{\text {Coworker }}^{a}\right)$, where $y(i)_{\text {Coworker }}^{a}$ denotes $i$ 's estimate of what people in his occupation actually earn and $y(i)_{\text {Coworker }}^{e}$ denotes what individual $i$ thinks that people in his occupation ought to earn.

\section{Mobility}

I use the difference between the following two scales to construct a simple index of (upward) mobility: (1) "In our society there are groups which tend to be towards the top and groups which tend to be toward the bottom. Below is a scale that runs from top to bottom. Where would you put yourself on this scale?" (2) "And ten years ago, where did you fit in then?"

Both scales range from 1 ("very bottom") to 10 ("very top"). The index of social mobility is measured as position today minus position ten years ago and so possible values range from -9 to +9 (with higher values indicating more upward mobility). 
Needs

This variable is a simple scale constructed from two different variables: "In deciding how much people ought to earn, how important should each of these things be, in your opinion?" (1) "What is needed to support your family." (2) "Whether the person has children to support."

The original two variables range from 1 ("strong disagreement") to 5 ("strong agreement"). The scale that used in the analysis is the simple average over these two items and therefore also ranges from 1 to 5 . (The four regressors discussed below are constructed in an analogous way.)

\section{Effort}

A scale made up of five different questions: "In deciding how much people ought to earn, how important should each of these things be, in your opinion?" (1) "How much responsibility goes with the job." (2) "The number of years spent in education and training." (3) "Whether the job requires supervising others." (4) "How well he or she does the job." (5) "How hard he or she works at the job."

\section{Ascribed skills}

Underlying this scale are two questions related to whether ascribed characteristics are important for getting ahead in life: "We have some questions about opportunities for getting ahead." (1) "How important is coming from a wealthy family?" (2) "Knowing the right people?"

\section{Acquired skills}

This scale is generated from two items. The two items reflect to what extent people think that acquired skills are important in determining one's pay: "We have some questions about opportunities for getting ahead." (1) "Do you agree or disagree? In Austria, people get rewarded for their effort." (2) "In Austria, people get rewarded for their intelligence and skills."

\section{Perception of conflicts}

Another scale, constructed from five different questions about the perception of different conflict in society: "In all countries, there are differences or even conflicts between different social groups. In your opinion, in Austria how much conflict is there between..." (1) "Poor people and rich people?" (2) "The working class and the middle class?" (3) "Management and workers?" (4) "People at the top of society and people at the bottom?" (5) "Young people and older people?" 


\section{Appendix B: Additional table}

See Table 6

Table 6 Summary statistics

\begin{tabular}{|c|c|c|}
\hline & Mean & $\begin{array}{l}\text { Standard } \\
\text { deviation }\end{array}$ \\
\hline \multicolumn{3}{|l|}{ A. Self interest } \\
\hline Family income & $1,840.732$ & 674.853 \\
\hline $\ln ($ family income $)$ & 7.429 & 0.462 \\
\hline Income dissatisfaction & 1.190 & 0.539 \\
\hline Social mobility & 0.099 & 1.361 \\
\hline \multicolumn{3}{|l|}{ B. Perceptions and Norms } \\
\hline Should be important: needs & 3.438 & 0.929 \\
\hline Should be important: effort & 3.998 & 0.513 \\
\hline Is important: aquired skills & 3.283 & 0.856 \\
\hline Is important: ascribed skills & 3.343 & 0.958 \\
\hline \multicolumn{3}{|l|}{ C. Additional controls } \\
\hline Perception of conflicts & 2.148 & 0.535 \\
\hline Female: Yes $=1$ & 0.569 & 0.496 \\
\hline Age (years) & 48.873 & 16.699 \\
\hline Education (years) & 10.716 & 2.854 \\
\hline Household size & 2.579 & 1.202 \\
\hline Employed: Yes = 1 & 0.480 & 0.484 \\
\hline Retired: Yes $=1$ & 0.315 & 0.450 \\
\hline $\begin{array}{l}\text { Living in urban/suburban } \\
\text { region: Yes }=1\end{array}$ & 0.553 & 0.498 \\
\hline \multicolumn{3}{|l|}{ Regional dummies: } \\
\hline Tyrol & 0.059 & 0.237 \\
\hline Salzburg & 0.086 & 0.281 \\
\hline Upper Austria & 0.143 & 0.350 \\
\hline Carinthia & 0.103 & 0.305 \\
\hline Styria & 0.143 & 0.350 \\
\hline Burgenland & 0.044 & 0.205 \\
\hline Lower Austria & 0.184 & 0.388 \\
\hline Vienna & 0.218 & 0.413 \\
\hline Number of observations & 707 & \\
\hline
\end{tabular}

\section{References}

Alesina A, Angeletos G-M (2005) Fairness and redistribution. Am Econ Rev 95(4):960-980

Alesina A, Fuchs-Schündeln N (2007) Good-bye Lenin (or not?): the effect of communism on people's preferences. Am Econ Rev 97(4):1507-1528

Alesina A, Giuliano P (2009) Preferences for redistribution. NBER Working Paper No. 14825 
Alesina A, La Ferrara E (2005) Preferences for redistribution in the land of opportunities. J Public Econ 89(5-6):897-931

Allan J, Scruggs L (2004) Political partisanship and welfare state reform in advanced industrial societies. Am J Pol Sci 48(3):496-512

Bénabou R, Ok E (2001) Social mobility and the demand for redistribution: the poum hypothesis. Q J Econ 116(2):447-487

Bénabou R, Tirole J (2006) Belief in a just world and redistributive politics. Q J Econ 121(2):699-746

Borck R (2007) Voting, inequality and redistribution. J Econ Surv 21(1):90-109

Carsey T, Layman G (2006) Changing sides or changing minds? Party identification and policy preferences in the American electorate. Am J Pol Sci 50(2):464-477

Castles F, Mair P (1997) Left-right political scales. Eur J Polit Res 31(1):147-157

Clark AE, Oswald AJ (1996) Satisfaction and comparison income. J Public Econ 61(3):359-381

Corneo G, Grüner HP (2002) Individual preferences for political redistribution. J Public Econ 83:83-107

Dawes C, Fowler J, Johnson T, McElreath R, Smirnov O (2007) Egalitarian motives in humans. Nature 446:794-796

Di Tella R, Galiani S, Schargrodsky E (2007) The formation of beliefs: evidence from the allocation of land titles to squatters. Q J Econ 122(1):209-241

Fong C (2001) Social preferences, self-interest and the demand for redistribution. J Public Econ 82:225-246

Fong CM, Bowles S, Gintis H (2005) Behavioural motives for income redistribution. Aust Econ Rev 38(3):285-297

Gastwirth J, Glauberman M (1976) The interpolation of the Lorenz curve and Gini index from grouped data. Econometrica 44(3):479-483

Giuliano P, Spilimbergo A (2009) Growing up in a recession: beliefs and the macroeconomy. Working Paper 15321, National Bureau of Economic Research

Goren P (2005) Party identification and core political values. Am J Pol Sci 49(4):881-896

Guiso L, Sapienza P, Zingales L (2006) Does culture affect economic outcomes?. J Econ Perspect 23-48

Hofer H, Weber A (2002) Wage mobility in Austria 1986-1996. Labour Econ 9(4):563-577

Hofer H, Pichelmann K, Schuh A-U (2001) Price and quantity adjustments in the Austrian labour market. Appl Econ 33(5):581-592

Huber J, Inglehart R (1995) Expert interpretations of party space and party locations in 42 societies. Party Polit 1(1):73-111

Jasso G (1999) How much injustice is there in the world? Two new justice indexes. Am Sociol Rev 64(1):133-168

Knutsen O (1998) Expert judgements of the left-right location of political parties: a comparative longitudinal study. West Euro Polit 21(2):63-94

Korpi W, Palme J (2003) New politics and class politics in the context of austerity and globalization: welfare state regress in 18 countries, 1975-1995. Am Polit Sci Rev 97(03):425-446

Kuhn A (2009) In the eye of the beholder: subjective evaluations of wage inequality and the demand for redistribution. IZA Discussion Paper No. 4360

McGann A, Kitschelt H (2005) The radical right in the Alps: evolution of support for the Swiss SVP and Austrian FPÖ. Party Polit 11(2):147

Meltzer A, Richard S (1981) A rational theory of the size of government. J Polit Econ 89(5):914

OECD (2008) Growing unequal? Income distribution and poverty in OECD countries. Technical report, OECD

Osberg L, Smeeding T (2006) "Fair" inequality? Attitudes toward pay differentials: the United States in comparative perspective. Am Sociol Rev 71:450-473

Piketty T (1995) Social mobility and redistributive politics. Q J Econ 110(3):551-584

Roberts K (1977) Voting over income tax schedules. J Public Econ 8(3):329-340

Seeleib-Kaiser M, Van Dyk S, Roggenkamp M (2005) What do parties want? An analysis of programmatic social policy aims in Austria, Germany and the Netherlands. Euro J Soc Secur 7(2):115

Sen A (2000) Social justice and the distribution of income. In: Atkinson A, Bourguignon F (ed) Handbook of income distribution, vol. 1, chapter 1. Elsevier Science, Amsterdam pp 59-85

Senik C (2005) Income distribution and well-being: what can we learn from subjective data? J Econ Surv 19(1):43-63

Stutzer A, Lalive R (2004) The role of social work norms in job searching and subjective well-being. J Eur Econ Assoc 2(4):696-719

Wallerstein M, Golden M, Lange P (1997) Unions, employers' associations, and wage-setting institutions in Northern and Central Europe, 1950-1992. Ind Labor Relat Rev 50(3):379 